\title{
Turning Points as Opportunities to Partner with Patients Living with type 2 Diabetes or Prediabetes
}

\author{
Christy J. W. Ledford, PhD, Carla L. Fisher, PhD, Lauren A. Cafferty, \\ Jeremy T. Jackson, BA, Dean A. Seebusen, MD, MPH, and Paul F. Crawford, MD
}

Introduction: Understanding patients' perspectives about their diabetes and what causes those perspectives to shift is critical to building a treatment strategy with the patient and facilitating patient self-management behavior. Key "turning points" can provide crucial opportunities to enact a change in perspective. The goal of this study is to identify "turning points" that have significance to diabetes-related health.

Methods: Research coordinators interviewed 33 patients aged 25 to 65 diagnosed with type 2 diabetes mellitus or prediabetes at medical centers in Augusta, Georgia, and Las Vegas, Nevada.

Retrospective interview technique and turning point analysis was employed to plot health or diabetes management changes from diagnosis up to the present day. The constant comparative method was used to conduct a thematic analysis. Axial coding identified properties characterizing each turning point.

Results: Patients reported 5 interrelated turning points occurring at various times after diagnosis: 1) gaining knowledge, either through patients own research and/or a health care class; 2) making lifestyle changes, including exercising and healthier eating; 3) encountering a life-changing event/ transition, including events that derailed healthy behavior, motivated health behavior, and removed barriers to enacting healthy behavior; 4) receiving social support, either through holding patients accountable or encouraging them to enact healthy behavior; and 5) interacting with clinicians, such as medication changes or behavior changes critical to disease management.

Discussion: These turning points provide specific moments throughout diabetes care in which family physicians can effectively partner with patients. By prompting, facilitating, or attending to these turning points, family physicians can partner with patients throughout diabetes care. (J Am Board Fam Med 2020;33:211-219.)

Keywords: Disease Management, Family Physicians, Georgia, Health Behavior, Life Style, Nevada, Obesity, Prediabetes, Qualitative Research, Self-Management, Social Support, Type 2 Diabetes Mellitus

For family physicians, understanding patients' perspectives about diabetes is critical to building an effective treatment strategy. ${ }^{1-3}$ Central to most treatment plans is the paradigm of self-management. Self-managing diabetes includes individual behav-

This article was externally peer reviewed.

Submitted 11 April 2019; revised 1 October 2019; accepted 7 October 2019.

From the Department of Family Medicine, Uniformed Services University of the Health Sciences, Bethesda, MD (CJWL); College of Journalism \& Communications, UF Health Cancer Center, UF Health Center for Arts in Medicine, University of Florida, Gainesville, FL (CLF); Henry M. Jackson Foundation, Military Primary Care Research Network, Uniformed Services University of the Health Sciences, Department of Family Medicine, Bethesda, MD (LAC, JTJ); Department of Family Medicine, Augusta University, Augusta, GA (DAS); Department of Family Medicine, Nellis Family Medicine Residency, Mike O'Callaghan Military Medical Center, Las Vegas, NV (PFC).

Disclaimer: The opinions and assertions contained herein are the private views of the authors and are not to be iors such as adopting lower-fat diets and increasing physical activity. Following diagnosis, patients are charged with managing their daily behavior, likely requiring the alteration of long-held habits. ${ }^{4}$ By partnering with patients throughout diabetes care,

construed as official or as reflecting the views of the Henry M. Jackson Foundation, the Uniformed Services University of the Health Sciences, the US Air Force, or the US Department of Defense at large.

Funding: This study was funded by the Office of the Assistant Secretary of Defense for Health Affairs through the Defense Medical Research and Development Program under Award No. FMBB100383695.

Conflicts of interest: None.

Corresponding author: Jeremy T. Jackson, BA, Henry M. Jackson Foundation, Military Primary Care Research Network, Uniformed Services University of the Health Sciences, Department of Family Medicine, 4301 Jones Bridge Road, Bethesda, MD 20814 (E-mail: jtjackson@hjf. org). 
family physicians can support behavior change and self-management behaviors. ${ }^{5,6}$

Beginning at diagnosis, family physicians can impact patient self-management through the communication of diagnosis information. For some patients, hearing the diagnosis can prompt a change in lifestyle, ${ }^{7}$ but it is critical that patients accept the diagnosis before they can enact self-management or treatment behaviors. 8 Patients value the communication of a diagnosis when it is clear, well timed, and delivered with authority. ${ }^{10}$ The communicative interaction that surrounds the delivery of a diagnosis sets the tone for the disease and can determine whether patients participate in proven diabetes education interventions. ${ }^{11}$ After the diagnosis conversation, opportunities will continue to arise for the physician to partner with the patient through shared decision making ${ }^{12}$ for example, when clinical indicators prompt treatment intensification ${ }^{13}$ or at the point of progression from prediabetes (preDM) to type 2 diabetes mellitus (T2DM).

Knowing when to most effectively partner with patients throughout their care can be a challenge for family physicians due to the complexity of behavior change and difficulty fitting partnering conversations into the confines of a primary care encounter, within which multiple diagnoses, problems, and patient concerns compete for place and priority. ${ }^{14,15}$ Moreover, self-management is further complicated by psychosocial factors, ${ }^{16}$ including the effects of clinical depres$\operatorname{sion}^{17}$ and benefits of social support. ${ }^{18,19}$

Research has revealed that "turning points" can motivate patients to increase efforts in disease management, ${ }^{18}$ providing opportune times across care for family physicians to effectively partner with patients. The aim of this study is to identify turning points that have significant impact on patients' diabetes-related health and disease management.

\section{Methods}

\section{Recruitment and Sampling}

Results are from a mixed-methods study on diabetes beliefs and behavior conducted within a practice-based research network. To represent a diversity of patient perspectives, 2 medical centers were selected in different US geographical regions: Augusta, Georgia; and Las Vegas, Nevada. On Institutional Review Board (IRB) approval, research coordinators used electronic health records to identify patients who met age and diagnosis inclusion criteria: aged 25 to 65 years and diagnosed with T2DM or preDM. The patient population included military health system beneficiaries to include civilian family of active-duty service members and military retirees as well as active duty service members and military retirees themselves. Exclusion criteria included: undergoing current cancer treatment and diagnosis of schizophrenia. Recruitment letters, providing information about the study and asking patients to call the research team to volunteer for interviews, were mailed to 4851 patients across the 2 sites in September 2016. As patients called the research team to volunteer, interviews were conducted on a rolling basis. Following patient consent, interviews were conducted in private rooms within the clinical spaces at each medical center.

\section{Data Collection}

Retrospective interview technique, which uses a graph, and turning point analysis was employed. Turning point analysis is widely used to understand the changing nature of participant experiences, including with disease. ${ }^{20-23}$ On the retrospective interview technique graph the horizontal axis represents time. The vertical axis represents health with a 0 -to-5-point scale (5 as best health rating). Patients rate their health before diagnosis (baseline) and plot dots representing changes (turning points) encountered after diagnosis up to the present day they perceive impacted health or diabetes management. Patients label each point for easy reference and connect the dots with a line when done. The graph helps guides the interview, extracting details about how turning points impact health and disease management. Professional transcriptions resulted in 1739 pages of data. Multiple verification strategies ensured trustworthiness of the data, including maintaining memos, reflexivity/responsivity, maintaining methodological coherence/congruence, and rich description of findings. ${ }^{24}$

\section{Analysis}

A thematic analysis using the widely accepted constant comparative method was conducted. ${ }^{25}$ Two authors reviewed transcripts noting turning points. Data were first segmented by diagnosis (preDM or T2DM) and race, 2 factors that can influence individuals' health and illness experiences. ${ }^{26}$ Analyses were then collapsed when no differences could be attributed to these 2 factors. Three validated 
systematic steps for thematic analysis were used in the open coding process. ${ }^{27}$ First, is the discovery of concepts in which transcripts are reviewed to identify emergent concepts that represent turning points and conceptual codes (eg, labels) are assigned to text to identify these emergent phenomena. Step 2 involves grouping these conceptual codes into categories (ie, themes). This open coding was conducted by 1 investigator who conducted the analysis by originally segmented groups. An investigator with qualitative analysis expertise reviewed each analysis to ensure conceptual coding identified turning points and turning points were grouped categorically before analyzing more transcripts. Multiple meetings were held to discuss the interpretations and continuously refine the thematic codebook before analysis. Step 3 was conducted by the expert qualitative researcher. This step includes axial coding the data in which categories are further refined by identifying thematic properties-characteristics that define each category (ie, theme). This analytic step provides depth and understanding about how each impacted health and disease management. Thematic saturation was reached when at least $33 \%$ of participants reported a theme.

\section{Results}

Three team members conducted 33 interviews from October 2016 to August 2017. Data saturation was met after 24 interviews. We continued data collection with scheduled volunteers to confirm saturation, ensuring rigor in data collection and analysis. Patients reported they had been living with their respective diagnoses for an average of 7.73 years (SD, 5.84; range, 1-24 years). See Table 1 for interview participant demographics.

Patients diagnosed with either preDM or T2DM reported 5 turning points impacting health and/or disease management: 1) gaining knowledge, 2) making lifestyle changes, 3) encountering a life-changing event/transition, 4) receiving social support, and 5) interacting with clinicians. Turning points were interrelated, occurring at various times after diagnosis. First-hand accounts and thematic properties (italicized) richly illustrate themes.

\section{Theme 1: Gaining Knowledge}

Although knowledge acquisition could be overwhelming, patients described a turning point in their well-being and disease management when gaining diabetes-related knowledge. This turning point tended to occur early postdiagnosis and alleviated diagnosis-related distress. As 1 patient explained after diagnosis: "I felt a little depressed. But when I got some information-you knowknowledge is power. I felt a little-I will not say powerful-but I felt better" (patient 4). Patients gained knowledge via 2 primary channels (attending a bealth care clinic class and/or doing their own

Table 1. Sample Demographics for Patients Interviewed between October 2016 and April 2017 in Augusta, Georgia, and Las Vegas, Nevada

\begin{tabular}{|c|c|c|c|}
\hline & $\begin{array}{l}\text { Full Sample } \\
\quad(\mathrm{n}=33)\end{array}$ & $\begin{array}{l}\text { Patients Living with } \\
\text { Prediabetes }(\mathrm{n}=11)\end{array}$ & $\begin{array}{l}\text { Patients Diagnosed with } \\
\text { Type } 2 \text { Diabetes }(\mathrm{n}=22)\end{array}$ \\
\hline Mean age & 55.64 (S.D. 8.17) & 54.27 (S.D. 8.20) & 56.32 (S.D. 8.26) \\
\hline \multicolumn{4}{|l|}{ Race/ethnicity } \\
\hline Non-Hispanic white & $14(42.4 \%)$ & $4(36.4 \%)$ & $10(45.5 \%)$ \\
\hline Hispanic white & $2(6.1 \%)$ & $1(9.1 \%)$ & $1(4.5 \%)$ \\
\hline Non-Hispanic Black or African American & $11(33.3 \%)$ & $4(36.4 \%)$ & $7(31.8 \%)$ \\
\hline Non-Hispanic Asian American or Pacific Islander ${ }^{\mathrm{a}}$ & $5(15.2 \%)$ & $2(18.2 \%)$ & $3(13.6 \%)$ \\
\hline Hispanic Asian American or Pacific Islander ${ }^{a}$ & $1(3.0 \%)$ & 0 & $1(4.5 \%)$ \\
\hline \multicolumn{4}{|l|}{ Gender } \\
\hline Male & $16(48.5 \%)$ & $3(27.3 \%)$ & $13(59.1 \%)$ \\
\hline Female & $17(51.5 \%)$ & $8(72.7 \%)$ & $9(40.9 \%)$ \\
\hline \multicolumn{4}{|l|}{ Treatment modality } \\
\hline Oral medication & $16(48.5 \%)$ & $1(9.1 \%)$ & $15(68.2 \%)$ \\
\hline Oral and insulin & $5(15.2 \%)$ & 0 & $5(22.7 \%)$ \\
\hline None & $12(36.4 \%)$ & $10(90.9 \%)$ & $2(9.1 \%)$ \\
\hline
\end{tabular}

SD, Standard deviation.

${ }^{a}$ Including Thai, Filipino, and part Hawaiian. 
research). Knowledge largely centered on building disease management self-efficacy.

This participant's diagnosis experience illustrates how knowledge was acquired through both channels and impacted health and disease management ability:

Patient: I was missing a lot of the information about what is happening to me right now. [Doctor] did not say and I did not know what to ask. ... I was scared. I was worried. I was nervous ... It is got to be because a lack of information. ... I was scared of what to eat! ... When I got home and calmed down, I did Google to see what it was but still not fully understanding what it is. ... No handout [sent] home ... [just] I am turning you loose. ... That was kind of the way I felt for a good little while after that.

Interviewer: What helped you turn the corner?

Patient: The information. Doing the research, and certainly coming to the class- the diabetes class and having different medical professions ... telling us about this.... And the handouts. I could go back over there and see it and being made to understand. It can be controlled, but you have to do A, B, C. (patient 6)

Participants learned about the class because physicians suggested it or enrolled them at diagnosis. Some recalled being referred to take the class if they asked questions about diabetes during appointments. Patients described gaining knowledge critical to disease management self-efficacy which enhanced health, as this patient shared:

I lost about twenty pounds in the class, and even better than that, my blood sugar really got under control. It was amazing ... I think it had to have been the fat intake that was after I started watching-controlling my fat in grams of fat that I was eating. My blood sugar went down to reasonable numbers ... Since I've taken this lifestyle class I've been feeling better. (Patient 29)

Patients also attained knowledge via personal research, searching the internet for the term "diabetes" or visiting WebMD. In doing so, they learned what to eat or not eat and potential consequences of diabetes like loss of limbs. As 1 patient stated, "I've changed my diet a lot just based on what I read" (patient 3). Some patients declared they attained the most information from "self research":

Going onto the internet and reading stuff and reading books, reading Paleo diets and stuff like that. Things that would work for diabetics and things that gave me more confidence about making food choices and being able to live my life the way I used to, just with small adjustments to make room for the condition. (Patient 2)

\section{Theme 2: Making Lifestyle Changes}

Patients reported a turning point after making lifestyle changes to support healthier habits. At times, habits were described with attaining knowledge (previous theme). Lifestyle changes included 2 healthier habits (exercising and eating healthier) to maintain or lose weight and establish better glucose levels.

For instance, to become active, patients recalled running, walking, hiking, lifting weights, swimming, and joining gyms or activities (eg, dance groups). To eat healthier, patients joined diet plans or groups like Weight Watchers or Food Lovers for Life and read diet plan books. A patient living with preDM explained:

I've learned to behave myself because I love carbs and sweets. That's part of the problem and I didn't exercise. That didn't exactly help. That's changed. All that's completely 360 . When they told me for sure that I'm headed towards [diabetes], I knew the consequences, so I had to just jump right into it. It wasn't easy. ... But I had to. I had to. (Patient 11)

This turning point contributed to health improvements like less lethargy, feeling lighter, having more energy, losing weight, and reducing body mass index (BMI). Still, patients expressed that it was challenging to maintain lifestyle changes. At times, they "fell off the wagon." This was linked to another theme (experiencing an unexpected life event). Patients expressed that some lifestyle changes (eg, Weight Watchers) helped for "a while" but maintenance was difficult, particularly when they were not active duty, as outlined below:

When you're on active duty, you're like a Ferrari. When you come off of active duty, your body becomes like a big dump truck. [Laughter] I hate to say it like that because when you're on active duty you might have to exercise twice a day, five days a week, and that's the routine for twenty years. Then all of a sudden when you stop, I think your body said, "What is going on here?" I think that has something to do with it. I didn't stay as active as I was when I was on active duty ... When I retire, I said, "I'm not getting up and running no five miles. I'm not doing that 
anymore!” [Laughter] But I should've kept doing it. (Patient 3)

\section{Theme 3: Encountering a Life-Changing Event/ Transition}

As noted, patients described a turning point after life-changing events that enhanced or challenged health and disease management. These included unexpected events like changing jobs, relocating, getting sick, having surgery, being injured, and being deployed. These transitions had an impact in 1 of 3 ways: 1) an event that derailed healthy behavior, 2) an event that motivated bealthy behavior, or 3) an event that removed barriers that inbibited bealthy behavior.

For example, the following woman described how a life event became a turning point derailing her and her husband's healthy eating:

We went on Atkins. ... I would do every kind of baking and candies at Christmas and I lost 45 pounds through all that. ... But then I went and changed school districts the next year and started eating in the cafeteria every day, and I immediately gained 30 pounds back. (Patient 26)

Alternatively, patients encountered "wake-up calls" motivating them to enact healthier behavior (eg, being active). One patient had an operation for a brain tumor and recalled, "I need to start thinking about my health ... I got more cautious on some things." (patient 1)

Patients described stressful circumstances that inhibited diabetes management and healthy behavior. When those experiences ended (eg, retirement; ending deployments; moved; changed jobs), stress was removed, which enabled patients to behave healthier. However, these life events did not occur in a vacuum. Rather patients described multiple life events across the disease course, contributing to ups and downs with health/disease management. A patient illustrates this:

I was being deployed a lot ... [I] gained weight. ... [My] weight and stress is starting to get to me ... wasn't able to cope with raising a family, deployments and stress. I was overloaded ... I wasn't sure how to handle, because nobody talks to me about it, how to do it. ... I was a stress monster ... It puts a strain on a person. ... A lot of that [stress] raised my blood sugar. Obviously, the diet in the military wasn't good, okay. They'd serve a lot of carbs.... They had salads, but like I said, nobody touched the salad. ... [Then] I retired ... I got into a serious [car] accident. ... I gained weight. ... I was in the upswing until that ... [Then] I can't work. I can't work out. Then [I] got better. ... It just got better from there ... I feel more relaxed. I'm not stressed out. I love my job. (Patient 19)

\section{Theme 4: Receiving Social Support}

Patients also experienced turning points when they received social support via technology (eg, online support through Mastermind groups; using WeGo) or one's network (eg, family, friends, work). The support functioned as a turning point by 1) motivating patients to engage in or maintain healthier behavior, or 2) bolding them accountable for their disease management. This theme related to a previous turning point (making/maintaining lifestyle changes).

For example, patients reported that peer support via the clinic's educational programs helped them stay on track:

"I'm monitoring myself and they're monitoring me. ... Now I have to go and take my test and see what my blood sugar level is and so it made me moderate the way I eat." (Patient 16).

However, when patients' disease management improved, they were removed from the program. This was another turning point (lack of support). A patient explained:

It's kind of nice to have accountability. It's kind of nice to have, to know that somebody's going to be checking on you. ... A lot of people ... they know what they have to do. They just don't have the self-control or the motivation.... Sometimes it's just nice to ... know that there's one more person out there that's kind of keeping track. (Patient 17)

Similarly, peer-to-peer online groups motivated patients to be healthier:

I've got some guys that I'm kind of challenged with. ... We meet weekly online.... One of the challenges ... [is] what did you do to be better this week ... That's been a help, belonging to that group.... Belonging to that group has been a big change because I know every Monday we meet. (Patient 5)

Receiving support at home or work was also critical as this woman explained with her husband:

We're trying to go at least five days a week walking. ... We were talking about yesterday. We need to walk once, ride the bike once and then do weights. ... We have to do it together. I mean we just have to, because then we keep each other on track. ... That's why we do things together 
because then he keeps me honest; I keep him honest. (Patient 26)

At times, patients blended technology and inperson support and juxtaposed the importance of receiving support with a lack of support, showing how the supportive turning point impacted disease management:

My water [app] reminder makes the "glup, glup, glup" water sound. ... I got it turned to loud so then I drink my water. In my previous job, everybody used to laugh at me and make fun of me ... [saying] "It's time for you to drink your water!" And I'd drink my water. But with my new job, I got two ladies in there, and then we all got our big jugs, so we all be sitting there, "Okay, time to drink our water!" That makes it even better because now I got somebody to do it with. (Patient 13)

\section{Theme 5: Interacting with Clinicians}

Patients also described turning points after certain interactions with clinicians. Such interactions led to medication changes (enhancing health) or behavior changes critical to disease management (eg, starting to exercise, changing eating habits, monitoring glucose) and, thus, interrelated with lifestyle changes. Some patients had an interaction that contributed to medication changes that improved health or their physician told them they needed to develop healthier habits (eg, stop eating certain foods). Patients stressed the significance of the clinician's communication style (eg, being direct, not blaming the patient, personalizing the conversation, spending time with the patient and family). Participants noted the clinician's approach was different or appreciated because they were having "overwhelming feelings" (eg, embarrassment, frustration, fear, disappointment) on diagnosis or because they encountered negative clinical interactions.

For example, patients recalled interactions when they felt blamed for their diagnosis as this woman encountered. She described a turning point after a new clinician changed medications and whose communication approach she valued.

[She] was wonderful. ... Why didn't I see this person three years ago? First of all, she looked at me and said, "This isn't your fault." I had been going carb-free and still had high numbers, and she said, "This isn't you. You're going carb-free and you're exercising. She said, this is your body." ... She put me on [different medication]. Overnight (snapping sound)—Boom! My number came down. I haven't been over 145 since the spring. I lost ten pounds. I felt good. ... Now I know what I'm doing. I mean now I feel like I have control of it, and it's not just the aid of the meds. (Patient 7)

This patient described a turning point in her health and disease management after talking with a new clinician willing to "work with her":

She goes at my pace because that was my biggest thing. ... The endocrinologist [says] "Your A1c is like this. It needs to be here. You're going to take this much medicine now." So I'd feel sick and ... had a hard time complying. She's like, "Okay, let's work with you. Okay, take as much as you can tolerate". It's been so much easier for me to stay with it. (Patient 32)

\section{Discussion}

These 5 turning points provide specific moments throughout diabetes care in which family physicians can effectively partner with patients. Physicians can play a direct role in these potential turning points, prompt or encourage the turning points, or be alert to their patients experiencing them.

First, family physicians can play a direct role in 2 of the emerging turning points: gaining knowledge and interacting with clinicians. Many newly-diagnosed patients have limited prior medical knowledge of diabetes, increasing the importance of initial diabetes messages as an information source and as an influencer of their personal models of the disease. ${ }^{28,29}$ Patients newly diagnosed with diabetes have high information needs. ${ }^{30,31}$ Patients consistently cite their physicians as their preferred source of information, ${ }^{32}$ yet, increasingly seek information online. Patients prefer to validate online information with their health care team. ${ }^{33}$ Discussions with a family physician can help patients make sense of complicated and potentially conflicting information. ${ }^{34}$

The identification of interactions with clinicians as a turning point demonstrates that family physicians not only play a role in providing information but being a partner in care. Previous research demonstrates that patient perception of clinician communication and interpersonal skills is associated with diabetes outcomes. ${ }^{35}$ Results here make actionable recommendations to family physicians: be direct, do not blame the patient, personalize the conversation, and spend time with the patient and family. Physicians with strong interpersonal and 
communication skills can reduce patient perceptions of treatment burden and empower patients to feel confident in self-management. ${ }^{36}$

Second, family physicians can play a secondary role in gaining knowledge and can encourage patients in 2 additional turning points: making lifestyle changes and receiving social support. In addition to providing patient education themselves, physicians can encourage patient information seeking by providing "information prescriptions," ${ }^{37}$ in which the physician directs the patient to recommended online resources. Physicians can also refer patients to existing diabetes education programs. ${ }^{38,39}$ Diabetes education programs play a critical role in both developing the skills patients need to make lifestyle changes ${ }^{40-42}$ and introducing them to a group of peers who can fulfill support needs. Family physicians can also encourage patients to include family in their information seeking and education classes. Research shows the power of social support in disease management: as compared with patient-only education, including family caregivers in diabetes education may result in better glucose control. $^{43}$

Third, family physicians should be attentive to patients who are potentially encountering a lifechanging event/transition. Foundational principles of family medicine-continuity of care, ${ }^{44}$ biopsychosocial approach, ${ }^{45}$ incorporation of the family ${ }^{46}$ uniquely position family physicians to partner at this turning point. Especially when considered a "personal physician," family physicians can anticipate or know when a patient faces a life-changing transition. It is at these turning points that family physicians can become critical partners. When a life event derails healthy behaviors, the family physician can help the patient understand how something like a job change is connected to healthy eating and then help the patient adapt and find skills to accommodate the new situation. Conversely, when a life event motivates healthy behavior, the family physician can encourage the patient through his or her success.

Limitations of this study impact generalizability. The number of participants was relatively low; however, the main themes reached saturation suggesting that an adequate number of subjects were enrolled. Although this was a 2-center study with a diverse population, all patients had health insurance and equitable access to care. Therefore, findings may not be universally applicable to those without insurance. Findings are also based on self-report, which are subject to recall bias and social desirability bias. The interview method, using turning points, helped manage any limitation with recall due to self-report and time as it directed patients to recall meaningful moment-turning points that made an impact cognitively and behaviorally.

In line with a qualitative design, our goal was to engage in an exploratory study to better understand (from patients' viewpoints) turning points patients encountered that motivated them to engage in disease management, to highlight opportunities for physicians to intervene with their patients. Future quantitative study can explore variability in their experiences with these turning points based on factors such as health literacy, patient activation, care model, etc. In addition, we interviewed patients living with preDM or T2DM, as patients living with these 2 conditions can have similar perceptions of disease severity ${ }^{48}$ and may encounter similar turning points that impact their disease management behavior. Given the exploratory design, we segmented the analysis based on diagnosis to be sensitive to any differences in experience; however, differences did not emerge in this sample. Future studies should explore this further; data from this study can inform a new scale to identify differences in patients' experiences based on living with preDM or T2DM.

\section{Conclusion}

Using a turning point analysis, this study identified 5 common turning points significantly impacting patients' diabetes-related health and disease management. By prompting, facilitating, or attending to these turning points, family physicians can partner with patients throughout care along the spectrum of glucose tolerance.

We thank Heather Rider, Angela Seehusen, and Jasmyne Womack for their assistance with recruitment and data collection.

To see this article online, please go to: http://jabfm.org/content/ 33/2/211.full.

\section{References}

1. Hendriks M, Rademakers J. Relationships between patient activation, disease-specific knowledge and health outcomes among people with diabetes; a survey study. BMC Health Serv Res 2014;14:393. 
2. Sultan S, Attali C, Gilberg S, Zenasni F, Hartemann A. Physicians' understanding of patients' personal representations of their diabetes: accuracy and association with self-care. Psychol Health 2011;26:101-17.

3. Mc Sharry J, Bishop FL, Moss-Morris R, Kendrick $\mathrm{T}$. 'The chicken and egg thing': cognitive representations and self-management of multimorbidity in people with diabetes and depression. Psychol Health 2013;28:103-19.

4. Gomersall T, Madill A, Summers LK. A metasynthesis of the self-management of type 2 diabetes. Qual Health Res 2011;21:853-71.

5. Yarnall KS, Pollak KI, Ostbye T, Krause KM, Michener JL. Primary care: is there enough time for prevention?. Am J Public Health 2003;93:635-41.

6. Parchman ML, Flannagan D, Ferrer RL, Matamoras M. Communication competence, self-care behaviors and glucose control in patients with type 2 diabetes. Patient Educ Counsel 2009;77:55-9.

7. Owei I, Umekwe N, Ceesay F, Dagogo-Jack S. Awareness of prediabetes status and subsequent health behavior, body weight, and blood glucose levels. J Am Board Fam Med 2019;32:20-7.

8. Ijäs-Kallio T, Ruusuvuori J, Perakyla A. Patient resistance towards diagnosis in primary care: implications for concordance. Health (London) 2010;14: 505-22.

9. Ledford CJW, Villagran MM, Kreps GL, et al. "Practicing medicine": patient perceptions of physician communication and the process of prescription. Patient Educ Counsel 2010;80:384-92.

10. Parry O, Peel E, Douglas M, Lawton J. Patients in waiting: a qualitative study of type 2 diabetes patients' perceptions of diagnosis. Fam Pract 2004;21: 131-6.

11. Skinner TC, Carey ME, Cradock S, et al. Diabetes education and self-management for ongoing and newly diagnosed (DESMOND): process modelling of pilot study. Patient Educ Counsel 2006;64: 369-77.

12. Tamhane S, Rodriguez-Gutierrez R, Hargraves I, Montori VM. Shared decision-making in diabetes care. Curr Diab Rep 2015;112.

13. Manze M, Rose AJ, Orner MB, Berlowitz DR, Kressin NR. Understanding racial disparities in treatment intensification for hypertension management. J Gen Intern Med 2010;25:819-25.

14. Resnicow K, Page SE. Embracing chaos and complexity: a quantum change for public health. Am J Public Health 2008;98:1382-9.

15. Parchman ML, Pugh JA, Romero RL, Bowers KW. Competing demands or clinical inertia: the case of elevated glycosylated hemoglobin. Ann Fam Med 2007;5:196-201.

16. Coventry PA, Hays R, Dickens C, et al. Talking about depression: a qualitative study of barriers to managing depression in people with long term conditions in primary care. BMC Fam Pract 2011;10.

17. Rush WA, Whitebird RR, Rush MR, Solberg LI, O'Connor PJ. Depression in patients with diabetes: does it impact clinical goals? J Am Board Fam Med 2008;21:392-7.

18. Madden MH, Tomsik P, Terchek J, et al. Keys to successful diabetes self-management for uninsured patients: social support, observational learning, and turning points: a safety net providers' strategic alliance study. J Nat Med Assoc 2011;103:257-64.

19. Gallant MP, Spitze GD, Prohaska TR. Help or hindrance? How family and friends influence chronic illness self-management among older adults. Res Aging 2007;29:375-409.

20. Baxter LA, Bullis C. Turning points in developing romantic relationships. Human Comm Res 1986; 12:469-93.

21. Fisher CL. Coping together, side by side: Enriching mother-daughter communication across the breast cancer journey. New York, NY: Hampton Press; 2014.

22. Fisher CL, Nussbaum JL. "Linked lives": Motheradult daughter communication after a breast cancer diagnosis. In: Dickson FC, Webb LM, eds. Communication for families in crisis: theories, research, strategies. New York: Peter Lang; 2012, 179-204.

23. Huston TL, Surra CA, Fitzgerald NM, Cate RM. From courtship to marriage: Mate selection as an interpersonal process. Personal Relationships 1981;2:53-88.

24. Morse JM, Barrett M, Mayan M, Olson K, Spiers J. Verification strategies for establishing reliability and validity in qualitative research. Int $\mathrm{J}$ Qual Methods 2002;1:13-22.

25. Glaser BG, Strauss AL. The discovery of grounded research: strategies for qualitative research. New York, NY: Aldine De Gruyter; 1967.

26. Ledford CJ, Seehusen DA, Crawford PF. Geographic and race/ethnicity differences in patient perceptions of diabetes. J Prim Care Commun Health 2019;10: 2150132719845819.

27. Strauss A, Corbin J. Basics of qualitative research techniques. Thousand Oaks, CA: Sage publications; 1998.

28. Lawson VL, Bundy C, Harvey JN. The influence of health threat communication and personality traits on personal models of diabetes in newly diagnosed diabetic patients. Diabetic Med 2007;24:883-91.

29. Lawson VL, Bundy C, Harvey JN. The development of personal models of diabetes in the first 2 years after diagnosis: a prospective longitudinal study. Diabetic Med 2008;25:482-90.

30. Biernatzki L, Kuske S, Genz J, et al. Information needs in people with diabetes mellitus: a systematic review. Syst Rev 2018;27. 
31. Peel E, Parry O, Douglas M, Lawton J. Diagnosis of type 2 diabetes: a qualitative analysis of patients' emotional reactions and views about information provision. Patient Educ Counsel 2004;53:269-75.

32. Hesse BW, Nelson DE, Kreps GL, et al. Trust and sources of health information: the impact of the Internet and its implications for health care providers: findings from the first Health Information National Trends Survey. Arch Intern Med 2005;165:2618-24.

33. Kuske S, Schiereck T, Grobosch S, et al. Diabetesrelated information-seeking behaviour: a systematic review. Syst Rev 2017;212.

34. Longo DR, Schubert SL, Wright BA, LeMaster J, Williams CD, Clore JN. Health information seeking, receipt, and use in diabetes self-management. Ann Fam Med 2010;8:334-40.

35. White RO, Eden S, Wallston KA, et al. Health communication, self-care, and treatment satisfaction among low-income diabetes patients in a public health setting. Patient Education Counsel 2015;98: 144-9.

36. Eton DT, Ridgeway JL, Linzer M, et al. Healthcare provider relational quality is associated with better self-management and less treatment burden in people with multiple chronic conditions. PPA 2017;11: 1635-46.

37. Burke M, Carey P, Haines L, Lampson AP, Pond F. Implementing the information prescription protocol in a family medicine practice: a case study. J Med Libr Assoc 2010;98:228-34.

38. Crawford P, Wiltz S. Participation in the journey to life conversation map improves control of hypertension, diabetes, and hypercholesterolemia. J Am Board Fam Med 2015;28:767-71.

39. Knowler WC, Fowler SE, Hamman RF, et al. 10year follow-up of diabetes incidence and weight loss in the Diabetes Prevention Program Outcomes Study. Lancet 2009;374:1677-86.

40. North SL, Palmer GA. Outcome analysis of hemoglobin A1c, weight, and blood pressure in a VA diabetes education program. J Nutr Educ Behav 2015;47:28-35.

41. Peek ME, Harmon SA, Scott SJ, et al. Culturally tailoring patient education and communication skills training to empower African-Americans with diabetes. Behav Med Pract Policy Res 2012;2:296308.

42. Kirk JK, Devoid HM, Strickland CG. Educational strategies of diabetes group medical visits: a review. CDR 2018;14:227-36.

43. Gomes LC, Coelho ACM, Gomides DDS, FossFreitas MC, Foss MC, Pace AE. Contribution of family social support to the metabolic control of people with diabetes mellitus: a randomized controlled clinical trial. Appl Nurs Res 2017;36: 68-76.

44. Lustman A, Comaneshter D, Vinker S. Interpersonal continuity of care and type two diabetes. Prim Care Diabetes 2016;10:165-70.

45. Burkett GL. Culture, illness, and the biopsychosocial model. Fam Med 1991;23:287-91.

46. Daaleman TP, Elder GH Jr. Family medicine and the life course paradigm. J Am Board Fam Med 2007;20:85-92.

47. Colwill JM, Frey JJ, Baird MA, Kirk JW, Rosser WW. Patient relationships and the personal physician in tomorrow's health system: a perspective from the Keystone IV conference. J Am Board Fam Med 2016;29:S54-S59.

48. Seehusen DA, Fisher CL, Rider HA, et al. Exploring patient perspectives of prediabetes and diabetes severity: a qualitative study. Psychol Health 2019;34:1314-1327. 